\title{
Tanzanian men's gender attitudes, HIV knowledge, and risk behaviours
}

\author{
Lisa A. Cubbins ${ }^{1 *}$, Lucy P. Jordan ${ }^{2}$ and Stephen E.D. Nsimba ${ }^{3}$ \\ ${ }^{1}$ Battelle, 1100 Dexter Avenue N., Suite 400, Seattle, WA, USA 98109-3598 \\ Phone: +206-528-3019; Fax: +206-528-3552 \\ cubbinsl@battelle.org \\ ${ }^{2}$ University of Hong Kong, Department of Social Work and Social Administration, Room CCC 541, \\ Jockey Club Tower, The Centennial Campus, Hong Kong (SAR) \\ Phone: +852-3917-1094 \\ jordanlp@hku.hk \\ ${ }^{3}$ University of Dodoma, College of Health Sciences, School of Medicine and Dentistry \\ P. O. Box 259, Dodoma, Tanzania. \\ Phone: +255-758539287/713-318113 \\ nsimbastephen@yahoo.co.uk
}

\begin{abstract}
This study uses data from the 2004-05 Tanzanian Demographic and Health Survey to examine whether men's traditional gender role attitudes contribute to their sexual risk behaviours for H IV. Logistic regression with random effects were used to analyze effects on risk behaviours at last sex (partners being drunk and condom use) with the three most recent sexual relationships. Men's traditional gender attitudes increased risky sexual behaviours (e.g., not using a condom) even when they had accurate knowledge regarding HIV risks. The impact of men's gender attitudes and HIV knowledge on risky sexual behaviours did not vary by relationship type. Unexpectedly, condom use was more likely when either partner was drunk compared to neither being drunk, though the protective impact of HIV knowledge remained. Overall, these findings suggest that traditional gender attitudes present barriers to preventing HIV/AIDS that even increased knowledge about HIV risks may not overcome.
\end{abstract}

Keywords: Tanzania; HIV risks; alcohol; condom use; gender attitudes

\section{Résumé}

Cette étude utilise la tanzanienne 2004-2005 Enquête Démographique et de Santé à examiner les attitudes d'hommes traditionnel du genre et les comportements à risque pour le VIH. Régression logistique avec effets aléatoires ont été utilisés pour analyser les effets sur les comportements à risque au cours du dernier rapport sexuel (les partenaires étant ivre et utilisation du préservatif) avec les trois dernières relations sexuelles. Les hommes des attitudes traditionnels du genre augmenté les attitudes comportements sexuels à risque même lorsqu'ils avaient connaissance précise concernant le VIH risques. L'impact des attitudes du genre et connaissance sur le VIH sur les comportements à risque ne varie pas selon les types de relations. Subitement, I'utilisation du préservatif était plus probable lorsque l'un ou l'autre des partenaires était en état d'ébriété par rapport à ni être ivre, bien que l'effet protecteur des connaissances sur le VIH est restée. Ces résultats suggèrent que les attitudes traditionnels présenter des obstacles à la prévention du VIH/SIDA que même un accroissement des connaissances sur les risques de VIH ne peuvent surmonter.

Mots clé: La Tanzanie; risqué de VIH; l'utilisation du preservative; attitudes de genre

\footnotetext{
${ }^{*}$ Corresponding author
} 


\section{Introduction}

Key features of the AIDS epidemic in sub-Saharan Africa (SSA) are that the primary mode of transmission is through heterosexual contact and women are disproportionately affected. Along with monogamy or abstinence, condom use is one of the most effective methods for preventing the spread of HIV. However, condom use relies on the agreement of both partners. In SSA gender attitudes and practices tend to bolster men's dominance in sexual interactions (Campbell 1995; Weiss et al. 2000). Further, alcohol use is more common among men than women in SSA (O bot 2006) and may increase HIV risk when combined with sex (LaBrie et al. 2002) by reducing condom use.

The objective of this study is to provide a better understanding of how men's traditional gender attitudes affect sexual risk taking behaviours across different types of relationships. We use data from the Tanzania Demographic Health Survey (DHS) 2004-05 to investigate how gender attitudes are related to men's sexual risk behaviours with their three most recent sex partners. We also consider whether the impacts of men's gender attitudes and HIV knowledge on sexual risk taking are consistent across different types of relationships. For example, men with traditional gender views may insist on not using a condom even in risky sexual relationships. In contrast, having an accurate knowledge of HIV risks may increase the use of condoms, for example, in committed relationships (e.g., spouse or regular partner rather than casual or paid sexual relationships).

Tanzania is an important country on which to focus the study for two primary reasons. First, Tanzania has made significant progress in reducing the rate of HIV, though these health gains may be challenged by recent increases in certain risk behaviours. Since 2000, trends HIV prevalence and incidence in Tanzania indicate that more people are adopting safe sexual behaviours (UNAIDS 2013). The estimated HIV prevalence among adults ages 15 to 49 was 5.1 percent in 2012, down from 7.5 percent in 2001. Similar declines occurred in the estimated number of new HIV infections for those 15 years or older: 130,000 in 2001 and 83,000 in 2012. These changes may be linked to certain significantly decreased behavioural risks in the population, including proportionally more men (ages 15 to 24) being knowledgeable about HIV prevention and condom use rising among people (ages 15 to 49) with multiple sexual partners. At the same, there are concerning increases in HIV-related risks (UNAIDS 2013). Between 2004 and 2010, Tanzania has seen significant increases in HIV risk with proportionally fewer young women (ages 15 to 24) having accurate knowledge about HIV prevention and proportionally more men and women (ages 15 to 49) having multiple partners over the course of a year.

Second, since 2004 there have been significant efforts in Tanzania to improve the status of women through government programs and policy changes, including expanding women's political influence, economic rights, and protections against genderbased violence (Denmark Ministry of Foreign Affairs and Government of Tanzania n.d.; Legal and Human Rights Centre 2009; OECD 2010). Though Tanzanian women continue to face major inequities (e.g., $33 \%$ of women were victims of domestic violence in the past year; Wane and Morisset 2012), these social structural changes may significantly alter gender relations over time. Thus, our analysis of the Tanzania DHS 2004-2005 data provides an important baseline comparison for assessing whether government policies targeting women's empowerment will translate into changes in sexual risk taking that affects both men and women.

\section{Literature Review and Theoretical Framework}

Alcohol use and abuse (e.g., being drunk) when having sex contributes to HIV risk (LaBrie et al. 2002) through a complex mixture of pharmacological and psychological mechanisms, including the drinker's socio-cultural beliefs, characteristics, and personality and the context of alcohol use (Fergusson and Lynskey 1996). Key to the alcohol-HIV risk connection is the concept of disinhibition (i.e., activation of behaviours normally suppressed by various controlling influences) (Woods and Mansfield 1983). Disinhibition theory suggests that alcohol causes a variety of individual physiological and psychological changes that disarm the forces holding back impulsive behaviour (Kallmén and Gustafson 1998), including behaviours that are normally avoided or suppressed (Room and Collins 1983). So alcohol use may lead increase HIVrelated risk behaviours (e.g., decreased condom use, having multiple partners) (Dermen et al. 1998; LaBrie et al. 2002). Heightening these risks are cultural beliefs particularly common among some African men that alcohol will enhance sexual activity and desires, encouraging partners to drink before sex (Kalichman et al. 2007b; Morojele et al. 2006). However, some research shows alcohol to have a 
protective influence or no effect on HIV risk (Kalichman et al. 2007b; Mataure et al. 2002).

Since the start of the HIV/AIDS epidemic in SSA, condom use has increased (Norman 2003) even among young adult males (Sayles et al. 2006). Still, there is evidence of inconsistent use partly due to cultural beliefs on use in particular relationships (Dilger 2003; Haram 2005; Moore and Oppong 2007). Beliefs against condom use in marital or steady relationships may be partly due to a partner's desire for childbearing, not wanting to be seen as unclean or diseased, or feeling that condoms diminish sexual pleasure (Brown et al. 2005; Dilger 2003; Moore and Oppong 2007). In contrast, condom use appears to be more consistent in relationships with casual or paid partners than steady ones (Dilger 2003).

Gender is a social construct regarding culturebound conventions, roles, and behaviours for women and men, as well as relations between them (Kreiger 2003). In many sub-Saharan African cultures, and much of Tanzania, traditional gender roles dictate the primacy of male control over most aspects of women's lives including household and family decision-making (Ampofo, 2001; Campbell 1995; Tolhurst and $N$ yonator 2005). The gendered socialization process emphasizes a dominant, and aggressive role in sexual relationships for men, and a submissive, 'chaste' role for women (Campbell 1995; Marsten and King 2006; Taegtmeyer et al. 2006; W eiss et al. 2000).

Studies from Tanzania specifically indicate that gender is an influential factor contributing to the spread of HIV/AIDS. Gender influences sexual relations (Haram 2005), proscribes strict role assignments (Dilger 2003; Lugalla et al. 1999), and even in communities with matrilineal social structures, patriarchal attitudes about male dominance prevail (Ampofo 2001). Expectations regarding gender roles likely contribute to HIV risk. For example, in Tanzania, there are cultural pressures for men to adhere to social standards regarding sexual prowess and promiscuity (Dilger 2003), and numerous studies confirm that having multiple sex partners is a risk factor for HIV infection (Auvert et al. 2001; Mnyika et al. 1997; Zoysa et al. 1996). Although the formal practice of polygamy has decreased across Tanzania, extramarital affairs and the incidence of concurrent partners remains a common practice for many men (Haram 2005). Some research suggests that polygamy (compared to other types of multiple partnerships) may act as a protective factor (Gausset
2001), but there is also support for polygamy as a risk factor (Haram 2005). These studies provide important information about the applicability of a gender framework in the examination of male sexual risk behaviours in Tanzania.

In this study using data from 2004-2005, we expect that Tanzanian men who have traditional gender role attitudes to be more likely to engage in risky sexual behaviour (e.g., combining excessive drinking and sex, not using a condom) even when there is accurate knowledge about HIV risks. That is, we expect traditional gender attitudes to be associated with riskier sexual behaviours despite awareness of HIV risks associated with the riskier sexual behaviour. Though some past studies of gender attitudes and sexual risks analyze both genders (e.g., Letamo 2011), we focus solely on men given their typically more powerful position physically, culturally, and economically relative to their female sexual partner. Further, we address the question of whether men's gender attitudes and HIV knowledge have the same effect on sexual risk behaviours with different types of partners. Based on past research (Dilger 2003; Lagarde et al. 2001), we expect that men will be less likely to engage in risky sexual behaviours (e.g., not using a condom or combining alcohol and sex) with casual or other partners they know less well, such as paid sex partners. However, it is not known whether traditional gender attitudes or accurate HIV knowledge alter the impact of relationship type on HIV-related sexual behaviours. Though some men may be unwilling to use condoms because of their traditional gender views, they may be more inclined to use a condom if their sexual partner is less familiar to them (e.g., casual sex partner). Whether a man acts upon his traditional gender attitudes (e.g., refusing to use a condom because it conflicts with a traditional masculinity) may shift if the action entails greater health risks (e.g., not using a condom with a casual or paid partner may increase his risk for acquiring HIV). Similarly, accurate awareness of HIV risks may lead some men to continue to use condoms in less risky relationships (e.g., with spouses or steady partners).

We analyze 2004-2005 Tanzanian DHS data that were collected just prior to major government policy changes and program efforts to promote the status of Tanzanian women (Legal and Human Rights Centre 2009; OECD 2010). O ur study provides an important comparison point describing the relationship between men's gender attitudes and sexual risk taking that existed in Tanzania before 
significant efforts to increase gender equality. As such, our study provides a baseline to which future studies can evaluate how these gender-focused state efforts may (or may not) have changed the gender dynamics of HIV risk behaviours.

Finally, we address the question of whether the disinhibiting effects of alcohol extend to countering the impact of protective factors (e.g., accurate knowledge of HIV risks) or, alternatively, amplifying the influence of risks factors (e.g., having paid sex) on condom use. In testing for these relationships, we include controls for other factors that may be associated with both the key predictor variables and the dependent variables, sexual risk behaviours. These include measures of demographic factors, socio-economic factors, and past sexual behaviour.

\section{Data and Methods}

Data.

For the analysis we use data from the Tanzania Standard DHS for 2004-05, a nationally representative survey (N BS and ORC Macro 2005). $D$ ata for the survey were collected in-person from women (15-49) and men (ages 15-49) through a multistage probability household sample (see NBS and ORC Macro 2005 for additional details). Response rates were very high for eligible households (99\%), women (97\%), and men $(92 \%)$. The full sample includes 10,329 women, and 2,635 men. The current study focuses on men from the Tanzanian mainland who reported on the last three sexual relationships in the past year (1,599 men). After deleting cases with missing data, our analysis sample included 2,135 relationships self-reported by the 1,555 men in our sample. In Table 1, we provide descriptive statistics on the sample of Tanzanian men included in our analysis.

Measures.

We include measures of the two dependent variables: whether either partner was drunk when they engaged in sexual behaviour and whether a condom was used. Both measures refer to the last time the partners had sex and are binomial. All our binomial variables are coded: $0=$ no, $1=$ yes. Among the relationships used in the analysis, at last sex one or both partners were drunk in 5.4 percent of the relationships, and a condom was used in 26.7 percent of the relationships. 
Table 1: Unweighted Descriptive Statistics on the Subsample of Sexually Active Men from the Tanzanian Demographic Health Survey, 2004-05 (N=1,555)

\begin{tabular}{|c|c|c|c|}
\hline Variable & Mean & (sd) & Percent \\
\hline$\overline{\text { Age }}$ & $3 \overline{0.61}$ & $(9 . \overline{01})$ & \\
\hline \multicolumn{4}{|l|}{ Marital status } \\
\hline Currently married & & & 68.94 \\
\hline Previously married & & & 5.92 \\
\hline $\mathrm{N}$ ever married & & & 25.14 \\
\hline Low education & & & 33.44 \\
\hline Has paid work & & & 61.41 \\
\hline Medium to high wealth & & & 58.01 \\
\hline \multicolumn{4}{|l|}{ Religious affiliation } \\
\hline Muslim & & & 31.64 \\
\hline Catholic & & & 29.20 \\
\hline Protestant & & & 26.30 \\
\hline None or other & & & 12.86 \\
\hline Accurate knowledge of HIV Risks & & & 75.63 \\
\hline Woman's right to ask for condom use & & & 56.14 \\
\hline Can get condom & & & 88.49 \\
\hline Has high media exposure & & & 61.03 \\
\hline Is circumcised & & & 72.28 \\
\hline Husband's reaction to wife refusal of sex & -.05 & $(.97)$ & \\
\hline \multicolumn{4}{|l|}{ N umber of partners in past 12 months } \\
\hline One & & & 69.65 \\
\hline Two & & & 23.22 \\
\hline Three or more & & & 7.14 \\
\hline \multicolumn{4}{|l|}{ Region } \\
\hline Lake & & & 14.21 \\
\hline North & & & 12.41 \\
\hline East & & & 17.17 \\
\hline Southern Highlands & & & 29.00 \\
\hline Central & & & 27.20 \\
\hline
\end{tabular}

N ote: Unweighted $\mathrm{N}=1,555$. Statistics are based on unweighted data.

We include two indicators of men's gender attitudes related to sexual behaviour and HIV risk. Attitudes regarding a husband's reaction to his wife's refusal of sex is a factor score generated through Common Factor Analysis using Varimax Rotation (eigen value $=1.868 ;$ Cronbach's alpha $=.613$ ). The factor is based on responses to questions asking what a husband is justified in doing if his wife refuses sex (e.g., get angry; refuse financial support; force sex). Higher values indicate a more negative response (e.g., forced sex). The second gender attitudes measure is a binomial variable on whether a woman has the right to ask for condom use when having. Relationship type includes four types: married or cohabiting; regular girlfriend or fiancé (reference); casual; or, paid sex or another type of relationship. We use the DHS-constructed measure of comprehensive HIV knowledge that is based on a series of questions about HIV-related risky and protective behaviors, as well as misconceptions about HIV/AIDS. Our binomial measure indicates whether respondents have accurate knowledge about HIV risks. We also include binomial measures on whether the male respondents have high media exposure and access to condoms which may reflect greater knowledge about HIV risks or an ability to avoid them. Controls were included for age, marital status, number of sex partners in past year, whether circumcised, religious affiliation, whether has low education, whether has paid work, whether medium to high household wealth, and regional location.

\section{Data analysis.}

The unit of analysis is a relationship based on pooling the three most recent sexual partners during the past 12 months for each sexually active man in the DHS sample. For the multivariate analyses, we used random effects logistic regression analysis to take into account non-independence of observations (e.g., men contributing more than one relationship) and because of binary dependent variables. We used sample weights provided by DHS to generalize our results to the Tanzanian mainland population. For each outcome, we first estimated a model including the key predictor variables (e.g., gender attitudes, relationship type) and control variables (e.g., age). We then tested a set of interaction effects: gender attitudes with HIV knowledge; relationship type with gender attitudes; and, relationship type with HIV 
knowledge. For condom use, we also tested for whether the effects of men's gender attitudes, HIV knowledge, and relationship type varied depending on whether one or both partner(s) were drunk at last sex. We conducted model difference tests to determine whether added interaction terms significantly improved the models' explanatory strength. The final models include predictor variables significant for each specific outcome measure.

\section{Results}

Model 1 in Table 2 provides logistic regression results from the relationship-level analysis of whether either partner was drunk at last sex. Men's gender attitudes on women's right to ask for condom use and having accurate HIV knowledge both significantly reduced the likelihood that either partner was drunk at last sex. Concurrence of sexual activity and at least one partner being drunk was significantly more likely in a casual relationship or one that involves a paid partner compared to more committed relationships (e.g., regular girlfriend). Also significant were several control variables, indicating that concurrence of sex and a drunk partner was more likely when the male partner was older, previously married (vs. never married), had less education, has paid work, was Catholic (vs. Muslim), had multiple partners in the past year, or lived in the Lake region (vs. Southern Highlands). Our interaction tests showed that the impact of gender attitudes and HIV knowledge did not vary depending

Table 2: Results from Random Effects Logistic Regression Analysis of Concurrence of Drunk Partner(s) and Sex and of Condom Use

\begin{tabular}{|c|c|c|c|c|}
\hline \multirow[b]{2}{*}{ Variable } & \multicolumn{2}{|c|}{$\begin{array}{l}\text { Model 1: Concurrence of } \\
\text { Drunk Partner(s) and Sex }\end{array}$} & \multicolumn{2}{|c|}{ Model 2: Condom Use } \\
\hline & $\underline{b}$ & $(s d)$ & $\underline{b}$ & $(\mathrm{sd})$ \\
\hline$\overline{\text { Can get }}$ condom & - & -- & $2.15^{* * *}$ & $(.46)$ \\
\hline Has high media exposure & -- & -- & $.52 * *$ & $(.18)$ \\
\hline Accurate knowledge of HIV Risks & $-1.13^{* * *}$ & $(.26)$ & -- & -- \\
\hline Woman's right to ask for condom use & $-.71 * *$ & $(.27)$ & $.51 * *$ & $(.16)$ \\
\hline Husband's reaction to wife refusal of sex & -- & -- & $-.33 * * *$ & $(.09)$ \\
\hline Age & $.04 *$ & $(.02)$ & -- & -- \\
\hline \multicolumn{5}{|l|}{ Marital status } \\
\hline Currently married & .44 & $(.40)$ & -- & -- \\
\hline Previously married & $1.76 * * *$ & $(.48)$ & -- & -- \\
\hline Low education & $.56 *$ & $(.25)$ & $-.71 * * *$ & $(.18)$ \\
\hline Has paid work & $.69 *$ & $(.30)$ & -- & -- \\
\hline \multicolumn{5}{|l|}{ Religious affiliation } \\
\hline Catholic & $.80 *$ & $(.34)$ & -- & -- \\
\hline Protestant & .38 & $(.36)$ & -- & -- \\
\hline N one or other & -.30 & $(.47)$ & -- & -- \\
\hline \multicolumn{5}{|l|}{ Relationship type } \\
\hline W ife or cohabiting partner & -.56 & $(.35)$ & $-3.62 * * *$ & $(.28)$ \\
\hline Casual acquaintance & $.65^{*}$ & $(.31)$ & $.67 * * *$ & $(.18)$ \\
\hline Sex worker or other partner & $2.40 *$ & (1.19) & .41 & $(.97)$ \\
\hline \multicolumn{5}{|l|}{$\mathrm{N}$ umber of partners in last year } \\
\hline Two partners & $.68 *$ & $(.28)$ & .24 & $(.18)$ \\
\hline Three or more partners & $.73^{*}$ & $(.36)$ & $.47 *$ & $(.23)$ \\
\hline Is circumcised & -- & -- & $.70 * * *$ & $(.18)$ \\
\hline O ne or both partners were drunk at last sex & -- & -- & $.83^{*}$ & $(.33)$ \\
\hline \multicolumn{5}{|l|}{ Region } \\
\hline North & -.14 & $(.43)$ & -- & -- \\
\hline East & -.32 & $(.37)$ & -- & -- \\
\hline Southern Highlands & $-.86 *$ & $(.36)$ & -- & -- \\
\hline Central & -.72 & $(.40)$ & -- & -- \\
\hline Constant & $-5.32 * * *$ & $(.85)$ & $-3.65^{* * *}$ & $(.54)$ \\
\hline Model chi-square (df) & $80.74 * * *$ & (19) & $195.26 * * *$ & (13) \\
\hline
\end{tabular}


on relationship type, and the impact of men's traditional gender attitudes was not altered by accurate HIV knowledge.

Model 2 in Table 2 shows logistic regression results from our analysis of condom use at last sex in Tanzanian men's three most recent sexual relationships in the past year. Two gender attitude measures (men's attitudes on women's right to ask for condom use and their reaction to a wife's refusal to have sex) were significantly related to condom use and operated in the expected direction. Also, two indicators HIV knowledge (high media exposure and access to condoms) were significant and operate in the expected direction. However, preliminary tests showed that HIV knowledge was not related to condom use and thus was excluded from the final model. Condom use was less likely in married/cohabiting relationships and more likely in casual relationships compared to relationships with a regular girlfriend. However, condom use was equally likely in relationships with a regular girlfriend and in more risky relationships (e.g., with a sex worker) but likely if one of the partners was drunk at last sex or the male partner had multiple sex partners in the past year. Also, men who had higher education, had been circumcised, or were from medium-to-high wealth households were more likely than their counterparts to use a condom. Finally, our interaction tests provided no support for differences in effects related to gender attitudes, HIV knowledge, relationship type, or either partner being drunk at last sex.

We felt that our results showing that men's higher education, accurate HIV knowledge, media exposure, and access to condoms each contributed to a lower likelihood of sexual risk behaviours were meaningful both statistically and substantively. Notably education is a key factor in improving cognitive skills and, past research has shown that improved cognitive skills contribute to less gender stereotyping (Bigler 1995). To investigate these findings further, we conducted post-hoc tests on the link between men's education and safer sexual behaviors.

Table 3 provides correlation coefficients between having a lower education and measures related to HIV knowledge, as well as traditional gender attitudes for the DHS sample of Tanzanian men. $\mathrm{N}$ ot surprisingly, in our sample lower education is significantly and negatively associated with accurate HIV knowledge, media exposure, and access to condoms. Importantly, though, our post-hoc tests also show that lower education is significantly and positively correlated with multiple measures of traditional gender attitudes, including approval of wife beating, husband's hostile reaction to his wife's refusal of sex, and the husband being the primary decision maker about the number of children a couple has, how to spend the wife's earnings, and decisions about large household purchases. Thus, men's lower education is linked to more traditional gender attitudes and to fewer information-based HIV protective factors (e.g., HIV knowledge, access to condom).

\section{Discussion}

In this study we addressed three research questions related to HIV risk for heterosexual partners. Do men's traditional gender attitudes contribute to risky sexual behaviors even when they are knowledgeable about their HIV risk? Do traditional gender attitudes or accurate HIV knowledge alter the impact of relationship type on risky sexual behaviors? And, does alcohol use weaken the impact of protective factors (e.g., HIV knowledge) or amplify the influence of risks factors (e.g., having paid sex) on condom use? 
Table 3: Correlation Coefficients for Low Education with HIV Knowledge Measures and Men's Traditional Gender Attitudes from the Tanzanian Demographic Health Survey, 2004-05 $(\mathbf{N}=1,555)$

Low Education with Measures of H IV Knowledge:

Accurate knowledge of HIV Risks

Has high media exposure

Can get condom

Low Education with Men's Traditional Gender Attitudes:

Approval of wife beating

Husband's hostile reaction to wife's refusal of sex

Husband primary decider on number of children

Husband primary decider on how to spend wife's earnings

Husband primary decider on large household purchases

$\underline{r}$

$-.163 * * *$

$-.176 * * *$

$-.225 * * *$

$.119 * * *$

$.150 * * *$

$.135^{* * *}$

$.111 * * *$

$.106 * * *$

N OTE: Shown are Pearson's correlation coefficients. Unweighted $N=1,555$. Statistics are based on w eighted data.

$* * * p<.001$

To answer these questions, we used the 2004-05 Tanzanian DHS to examine HIV-related risk behaviors in men's three most recent sexual relationships during the past year. We found that men's traditional gender attitudes do increase risky sexual behaviors, and this effect is not altered by accurate HIV knowledge. Further, the impact of men's gender attitudes and HIV knowledge on risky sexual behaviors does not vary across relationship types (i.e., same effect in committed and noncommitted relationships). Finally, we found that concurrence of being drunk and having sex did not alter the impact of other protective or risk factors. Somewhat unexpectedly, we found that condom use was more likely when one or both partners were drunk. It may be that the decision to use a condom may have occurred prior to beginning drinking; thus, taking precautions (e.g., using a condom) in anticipation of having sex when one or partners are drunk.

O ur findings are consistent with other research from Tanzania SSA showing that traditional gender attitudes are associated with sexual risk behaviors for HIV (e.g., Kalichman et al. 2007a; Masvawure et al. 2009). In our study, men who did not endorse a woman's right to refuse unprotected sex (i.e., no condom) were more likely to have had sex when either partner was drunk and less likely to use a condom. Similarly, Tanzanian men who approved of a husband's right to respond in a hostile manner if his wife refuses sex were less likely to use a condom. Further, the interaction test between gender attitudes and accurate HIV knowledge was not significant. It appears that traditional gender attitudes may present barriers to preventing HIV that increased knowledge about risks cannot overcome. Men's adoption of gender-equitable attitudes regarding sexual and contraceptive activities may reduce both gender's HIV risks overall. Further, our finding that the impact of gender attitudes and HIV knowledge does not vary across different types of relationships is important as it suggests that the promotion of gender equality may have similarly beneficial effects in committed married and cohabiting relationships, as well as less committed casual or transactional sexual relationships.

Recent research has tried to identify the process through which education lowers HIV-related risks in SSA, suggesting that the protective effect of education may be due to its role in developing higher order cognitive skills and health reasoning ability (Baker et al. 2010), as well as improved decision-making abilities (Peters et al. 2010). O ur post-hoc analyses suggest that the positive impact of men's education on safer sex practices also may be due to education increasing more gender equitable attitudes and behaviors, perhaps due to heightened cognitive skills (Bigler 1995). Expanding access to higher levels of education for both men and women in Tanzania and in other parts of SSA may have multiple beneficial consequences that extend to reducing gender bias, improving health reasoning and knowledge, and ultimately leading to better health outcomes for men and women. Reductions in gender bias also appear to contribute to less intimate partner violence in Tanzania (Krishnan et al. 2012) offering additional evidence that equitable gender relations may have multiple benefits for both men and women.

Finally, in this study we found that partners' being drunk and having sex did not alter the impact of other protective factors (e.g., access to condoms) or amplify other risk behaviors (e.g., engaging in sex 
with a paid partner). In addition, when either partner was drunk when having sex, the likelihood of using a condom actually increased. Past research provides some evidence that men have more consistent condom use with casual or paid partners than with regular or steady partners (Dilger 2003), and in this study combining alcohol with sex is most likely to occur in relationships involving casual and paid sex. As such, one interpretation of the unexpected findings of higher condom use when either partner is drunk is the use of condoms when there are multiple risks present. Although our interaction tests did not show a combined effect of partners being drunk and relationship type, we did find that the effect size of concurrent drunk partners and sex on condom use declined by 22 percent when relationship type was controlled and by 19 percent when number of partners in the last year was controlled. Thus at least part of the positive effect of concurrent drunk partners and sex on condom use is due to its occurrence with other risk behaviors. Additional research is needed to disentangle the factors contributing to the mixed findings found here and in other studies (Kalichman et al. 2007b; Mataure et al. 2002) on the effect of alcohol consumption on condom use and other HIVrelated risk behaviors, such as sexual violence, in the African context (George and Stoner 2000).

Although our study provides important insights, it is not without limitations. The 2004-05 Tanzanian DHS provides only cross-sectional data that makes it difficult to establish causal order, such as between the attitudinal and outcome measures. This makes it difficult for us to disentangle the ordering of certain behaviors (e.g., whether men decide to use a condom before combining alcohol and sex). Due to lack of data in the survey, we also do not have measures of power differences (e.g., education, earnings) between recent partners or the use of physical force or violence within the relationship. Inclusion of indicators on partners' social and economic power differences and use of violence or coercion would provide a fuller view of how gender inequities may contribute to HIV-related risks.

Finally, though we included measures of the link between male respondents and their social environment (e.g., media exposure), we do not have direct measures of the social environment that may play a large role in defining and changing normative relations between men and women. A future study might address how changes in the social environment, such as Tanzanian government actions to improve the status of women, may have altered both men's gender attitudes and their sexual risk taking behaviors. As our study uses data from the 2004-2005 Tanzanian DHS, it provides a baseline comparison point to determine whether changes in women's status have altered the nature or impact of Tanzanian men's gender attitudes on sexual risk behaviors.

\section{Conclusion}

O verall, this study provides support for policies aimed at promoting not only knowledge about HIV risks but also gender equity. Tanzania's policy changes related to gender may have broad effects not only socially and economically, but for health as well. Supporting Tanzanian men to adopt more gender equitable norms, attitudes, and behaviors may aid in their adoption of safer sexual practices. Similarly developing interventions and other health programs that are gender-sensitive and promote education for both genders may aid in decreasing the incidence of new HIV/AIDS infections among both men and women in SSA.

\section{Acknowledgement}

The project described was supported by Grant Number R03HD056962 from the Eunice Kennedy Shriver $\mathrm{N}$ ational Institute of $\mathrm{C}$ hild $\mathrm{H}$ ealth And Human Development. The content is solely the responsibility of the authors and does not necessarily represent the official views of the Eunice Kennedy Shriver $\mathrm{N}$ ational Institute of $\mathrm{C}$ hild $\mathrm{H}$ ealth And Human Development, the $\mathrm{N}$ ational Institutes of $\mathrm{Health}$, Battelle Memorial Institute, the University of Hong Kong, or the University of Dodoma. The authors thank the assigned reviewers at the African Population Studies for their helpful comments.

\section{Authors' Contribution}

As the lead author, Dr. Cubbins oversaw the development of each section of the paper. She also developed the research approach, contributed to the literature review, conducted the analysis, and lead preparation of the discussion and conclusion. Dr. Jordan contributed to the literature review, the construction of key variables, and contributed to the discussion. Dr. N simba contributed to the literature review and interpretation of results.

\section{Authors Guarantee Form:}

The authors (Dr. Lisa A. Cubbins, Dr. Lucy P. Jordan, and Dr. Stephen E.D. N simba) have each contributed to the content of this article. The content of this article has never been published previously. 


\section{References}

Ampofo, A.A 2001. "When men speak women listen: Gender socialization and young adolescents' attitudes to sexual and reproductive issues." African Journal of Reproductive Health 5, (3): 196-212.

Auvert, B., Buve, A., Ferry, B., Carael, M., Morison, L., Lagarde, E., Robinson, N.J., Kahindo, M., Chege, J., Rutenberg, N., Musonda, R., Laourou, M. and Akam, E 2001. "Ecological and individual level analysis of risk factors for HIV infection in four urban populations in sub-Saharan African with different levels of HIV infection." AIDS 15, (4): S15-30.

Baker D.P., Leon, J. and Collins, J.M 2010. "Facts, attitudes, and health reasoning about HIV and AID S: Explaining the education effect on condom use among adults in sub-Saharan Africa." AIDS and Behavior 15, (7): 1319-27.

Bigler, R.S 1995. "The role of classification skill in moderating environmental influences on children's gender stereotyping: A study of the functional use of gender in the classroom." Child Development 66, (4): 1072-1087.

Brown, _., Sorrell, 1. and Raffaelli, M 2005. "An exploratory study of constructions of masculinity, sexuality and HIV/AIDS in Namibia, Southern Africa." Culture, Health, and Sexuality 7, (6): 585-98.

Campbell, C 1995. "Male gender roles and sexuality: Implications for women's AIDS risk and prevention." Social Science and Medicine 41, (2): 197-210.

Denmark Ministry of Foreign Affairs and Government of Tanzania. (n.d.). Programme Support Document. Gender Equality and Women's Empowerment Programme II. Tanzania. 2012-2014. (Accessed May 1, 2014: http://tanzania.um.dk/en/ /media/T anzania/D ocu ments/H ealth/H ealth-Sector-ProgrammeSupport-D ocument-20092014.ashx)

Dermen, K.H., Cooper, M.L. and Agocha, V.B 1998. "Sex-related alcohol expectancies as moderators of the relationship between alcohol use and risky sex in adolescents." Journal of Studies on Alcohol 59, (1): 71-77.

Dilger, H 2003. "Sexuality, AIDS, and the lures of modernity: Reflexivity and morality among Young People in Rural Tanzania." Medical Anthropology 22, (1): 23-52.
Fergusson, D.M. and Lynskey, M.T 1996. "Alcohol misuse and adolescent sexual behaviors and risk taking." Pediatrics 98, (1): 91-96.

George, W.H. and Stoner, S.A 2000. "Understanding acute alcohol effects on sexual behavior." Annual Review of Sex Research 11, (1): 92-124.

Haram, L 2005. "AIDS and risk: The handling of uncertainty in northern Tanzania." Culture, Health and Sexuality 7, (1): 1-11.

Kalichman, S.C., Simbayi, L.C., Cain, D., Cherry, C., Henda, N. and Cloete, A 2007a. "Sexual assault, sexual risks and gender attitudes in a community sample of South African men." AIDS Care 19, (1): 20-27.

Kalichman, S., Simbayi, L., Kaufman, M., Cain, D. and Jooste, S 2007b. "Alcohol use and sexual risks for HIV/AIDS in sub-Saharan Africa: systematic review of empirical findings." Prevention Science 8, (2): 141-151.

Kallmén, $H$ and Gustafson, R 1998. "Alcohol and disinhibition." European Addiction Research 4 (4): 150-162.

Krieger, N 2003. "Genders, sexes, and health: What are the connections- and why does it matter?" International Journal of Epidemiology 32, (4): 652-657.

Krishnan, S., Vohra, D., de Walque, D., Medlin, C., N athan,R. and Dow, W.H 2012. "Tanzanian couples' perspectives on gender equity, relationship power, and intimate partner violence: findings from the RESPECT study." AIDS Research and Treatment Epub 2012 December 24.

LaBrie, J.W., Schiffman, J. and Earleywine, M 2002. "Expectancies specific to condom use mediate the alcohol and sexual risk relationship." Journal of Sexual Research 39, (2): 145-152.

Letamo, G 2011. "The influence of gender role attitudes on risky sexual behavior: Evidence from the 2008 Botswana AIDS impact survey III." African Population Studies 25, (2): 402-418.

Legal and Human Rights Centre 2009. Tanzania Human Rights Report 2008: Progress through Human Rights. Compilation of extracts on women's rights. (Accessed May 1, 2014: http://ww w.tanzania.go.tz/egov uploads/docume nts/T anzania human rights report 2008 women_s rights sw.pdf)

Masvawure, T.B., Terry, P.E., Adlis, S. and Mhloyi, M 2009. "When "no" means "yes": The gender implications of HIV programming in a 
Zimbabwean university." Journal of the International Association of Physicians in AIDS Care 8, (5): 291-298.

Mataure, P., McFarland, W., Fritz, K., Kim, A., Woelk, G., Ray, S. and Rutherford, G 2002. "Alcohol use and high-risk sexual behavior among adolescents and young adults in Harare, Zimbabwe." AIDS and Behavior 6, (3): 211-219.

Morojele, N., Kachieng'a, M. and Mokoko, E 2006. "Alcohol use and sexual behavior among risky drinkers and bar and shebeen patrons in Gauteng province, South Africa." Social Science and Medicine 62, (1): 217-227.

Moore, A. R. and Oppong, J 2007. "Sexual risk behavior among people living with HIV/AIDS in Togo." Social Science and Medicine 64, (5): 1057-1066.

NBS, and ORC Macro (N ational Bureau of Statistics (N BS) [Tanzania] and ORC Macro). 2005. Tanzania Demographic and Health Survey 200405. Dar es Salaam, Tanzania: N ational Bureau of Statistics and O RC Macro.

Niens, L. and Lowery, D 2009. "Gendered epidemiology: Sexuality equality and the prevalence of HIV/AIDS in sub-Saharan Africa." Social Science Q uarterly 90, (5): 1134-1144.

Norman, L.R 2003. "Predictors of consistent condom use: A hierarchical analysis of adults from Kenya, Tanzania and Trinidad." International Journal of STD and AIDS 14, (9): 584-590.

O bot, I.S 2006. "Alcohol use and related problems in Sub-Saharan Africa." African Journal of Drug and Alcohol Studies 5, (1): 17-26.

OECD (O rganisation for Economic Co-O peration and Development) 2010. Atlas of Gender and Development: How Social N orms Affect Gender Equality in Non-OECD Countries. (Accessed May 1, 2014: www.sourceoecd.org/development/9789264075 207)
Peters, E., Baker, D.P., Dieckmann, N.F., Leon, 1. and Collins, $\mid$ 2010. "Explaining the effect of education on health: a field study in Ghana." Psychological Science 21, (10): 1369-1376.

Room, R. and Collins, G. (eds) 1983. Alcohol and disinhibition: $N$ ature and meaning of the link. NIAAA Monograph 12. Washington, DC, US Department of $\mathrm{H}$ ealth and $\mathrm{H}$ uman Services.

Sayles, J.N., Pettifor, A., Wong, M.D., MacPhail, C., Lee, S.J., Hendrickson, E., Rees, H.V. and Coates, $T$ 2006. "Factors associated with self-efficacy for condom use and sexual negotiation among South African youth." Journal of Acquired Immune Deficiency Syndrome 43, (2): 226-233.

UN AIDS 2013. Global report: UNAIDS report on the global AIDS epidemic 2013. Joint U nited $\mathrm{N}$ ations Programme on HIV/AIDS.

Wane, W. and Morisset, J 2012. "Is this a woman's world? Gender equality in Tanzania." Africa Can End Poverty (Accessed April 29, 2014: http://blogs. worldbank.org/africacan/is-this-awomans-world-gender-equality-in-tanzania )

Weiss, E., Whelan, D. and Gupta, G.R 2000. "Gender, sexuality and HIV: making a difference in the lives of young women in developing countries." Sexual and Relationship Therapy 15, (3): 233-245.

Wingood, G.M. and DiClemente, R.J 2000. "Application of the theory of gender and power to examine HIV-related exposures, risk factors, and effective interventions for women." Health Education and Behavior 27, (5): 539-565.

Woods, S.C. and Mansfield, J.G 1983. "Ethanol and disinhibition: physiological and behavioural links." In: Room, R. and Collins, G., (eds), Alcohol and Disinhibition $N$ ature and Meaning of the Link. N IAAA Research Monograph 12, Washington, DC., U.S. Department of Health and Human Services, 4-23. 